EDITORIAL

\title{
Beyond descriptions: selected aspects of science and practice in clinical psychology and personality psychopathology
}

\author{
Emilia Soroko ${ }^{A, B, D, E, F}$, Dominika Górska $a^{A, B, D, E, F}$ \\ Institute of Psychology, Adam Mickiewicz University in Poznań, Poland
}

A ccording to the American Psychological Association, clinical psychology is the psychological specialty that provides continuing and comprehensive mental and behavioral health care for individuals and families; consultation to agencies and communities; training, education and supervision; and researchbased practice (APA, 2018). It is evident that clinical psychology is both a field of professional practice and a scientific discipline, and the task for the clinical psychologist is to link these two broad fields. According to Cierpiałkowska and Sęk (2016), clinical psychology is devoted to description (of mental health and disorders) and explanation (of mechanisms for mental health and disorders based on psychological theory and empirical research) in the context of biological, psychological, and sociocultural factors. We contend that scientific knowledge and practical knowledge are the bases for 1) proper diagnosis, assessment, case conceptualization, and treatment evaluation and 2) effective procedures for psychological help in the form of prevention, counseling, or psychotherapy.
As active participants in the field of clinical psychology, we have noticed three interrelated trends in scientists' and practitioners' discourse: 1) the persistence of an inconvenient discrepancy between science and practice (Cha \& DiVasto, 2017; Ready \& Santorelli, 2014; Reese et al., 2017; Smith \& Thew, $2017), 2)$ the expansion of a descriptive approach to mental phenomena (Cierpiałkowska, Groth, \& Kleka, 2018), and 3) the lack of theory in a significant number of studies (Cierpiałkowska \& Sęk, 2016). In the following paragraphs, we will briefly discuss these trends and present a list of major challenges facing research in the field of clinical psychology.

Brzeziński highlights (2017) that clinical practice only makes sense when referring directly to scientific knowledge created in the field of psychology research. Supported by this statement, we believe that, to a large extent, scientific research is directed toward giving practitioners the mental tools needed to understand the pathomechanisms and pathogenesis of psychological disorders. To be helpful for profes-

Corresponding Author - Emilia Soroko, Ph.D., Institute of Psychology, Adam Mickiewicz University in Poznań, 89 AB Szamarzewskiego Str., 60-568 Poznań, Poland, e-mail: Emilia.Soroko@amu.edu.pl

Authors' CONTribution - A: Study design · B: Data collection · C: Statistical analysis · D: Data interpretation

E: Manuscript preparation · F: Literature search · G: Funds collection

TO CITE THIS ARTICLE - Soroko, E., \& Górska, D. (2018). Beyond descriptions: selected aspects of science and practice

in clinical psychology and personality psychopathology. Current Issues in Personality Psychology, 6(4), $261-265$.

RECEIVED 18.09.2018 · REVIEWED 24.09.2018 · ACCEPTED 26.09.2018 · PUBLISHED 07.12.2018 
sionals, there is still a need to conduct research that is close to practice and grounded in major findings of general psychology. We believe that this perspective contributes not only to diminishing the perceived gap between science and practice in the mind of clinical psychologists but also to the acquisition of knowledge and reflection about salient clinical issues. The latter does not restrict us to observable phenomena, but the term "knowledge" is inseparable from understanding for which a firm, justified, and clinically useful theory is needed.

An important perspective, which we call a "theoryembedded" stance, is to some extent disregarded in scientific research in clinical psychology. We have observed this from reading scientific articles with a poorly delineated theoretical background (sometimes with none at all) or when the authors refrain from undertaking theoretical discussions through the prism of broadly used psychological theories. Taking into account the need to adjust to the general requirements of scientific writing and thinking, some research questions may have trouble seeing the light of day even though they are cognitively valuable, and the conclusions obtained are useful in practice. A purely descriptive approach to mental phenomena is sometimes welcomed by practitioners as it relieves the burden of uncertainty and ambiguity, especially when the working conditions are difficult and not supportive.

In science, rising from the descriptive level to the explanatory level and conducting research close to clinical practice undoubtedly involves taking a risk with more exploratory studies as opposed to direct verification of isolated theoretical assumptions. This sometimes leads to undesired forms of research design that are rather complex, multi-phasic, and involve multiple methods. As a consequence, we encounter some interrelated features of research projects: relatively small sample sizes, qualitative data collection methods (observational studies and/or semi-structured interviews), data analysis incorporating human assisted coding procedures with a requirement of reliability and validity testing, and/or reflexively used questionnaires (e.g., taking into account the conscious and unconscious motivations related to self-presentation) where a need arises to understand the results qualitatively. Therefore, nondeclarative methods of data collection carry extra weight in this case.

An attempt in scientific research to exceed a simple description of psychological phenomena should not only explain the dynamics of interrelations between psychological structures, but it should also understand their greater diversity and variability in situations of activation (or lack thereof) under the influence of social stimuli. It results in the inevitable confrontation of the researcher with the complexity of phenomena (e.g., symptoms or external manifesta- tions), the necessity to distinguish between the conditions of their appearance, and the need to reach for psychological theories that will allow this diversity to be understood. For example, internal structures that build the mental apparatus such as schemas, mental representations, or relational patterns manifest themselves in an intra-individually variable way (e.g., depending on the situational stimulus, latency vs. activation of emotional structures) at the level of motivation, emotion, interpersonal relations, perception of oneself and the world, personality traits, or regulatory strategies. This creates a very differentiated description that, at a certain level, might be full of contradictions, but at the same time provokes us to understand its nature and discover the rules that determine its dynamics and complexity (Cheftez, 2013; Sperry, 2013; Zhang \& Labouvie-Vief, 2004). The rules most likely reflect circular, systemic relations of an equifinal and equipotential character (Baltes, 1998; Gelo \& Salvatore, 2016; Pervin, 2001).

Thus, we would like to suggest the following approaches that deserve more attention in clinical psychology and that are relevant in view of the observations described above. We treat them as actual challenges faced by scientific clinical psychology.

1. Ask research questions that deal with pathomechanism and pathogenesis as opposed to restricting them to descriptive approaches. Such questions probe internal regulatory mechanisms, structures, and processes underlying symptoms. As a result, clinical practice is enriched by a comprehensive hypothesis about the patient's psychological functioning (Cierpiałkowska \& Sęk, 2016).

2. Trace psychological processes in their phasic nature in order to understand how certain regulatory processes are activated under specific circumstances and to observe a phenomenon as a process rather than a static state. We refer to both intrapsychic (e.g., unconscious priming, emotional processing) and interpersonal or situational (e.g., stress, psychotherapy) processes (e.g., Baker, 2018; Górska \& Soroko, 2017; Mergenthaler, 2008).

3. Answer research questions with theory-driven knowledge (paradigmatic or general psychological theory). In diagnostic practice, formulating a hypothesis (patient-specific model) of pathomechanism and pathogenesis requires mentalistic terms, namely terms for cognitive, emotional, and motivational activities, that cannot be fully captured with neuropsychological or behavioral terms. Empirical research results can be interpreted, explained, or translated into such terms that will increase the usefulness of a selected measure or a construct in clinical practice (see "clinical utility” in Mullins-Sweatt, Lengel, \& DeShong, 2016).

4. Use methods of data collection that are close to practice, such as semi-structured and unstructured interviews or questionnaires, while bearing 
in mind the context of elicitation of self-report data. This approach will enrich the data as much as possible and prevent reduction of the observations to numerical codes. At the same time, it retains the possibility of statistical hypothesis testing on relatively complex data.

5. Use methods of data analysis that are similar to the reasoning processes used by clinicians with special regard to possible judgmental errors (e.g., Garb, 2010; Westen \& Weinberger, 2005). This will provide tested examples of ordered ways of thinking that may contribute to the development of a competency of self-monitoring during assessment and intervention by systematized ways of dealing with different types of data and integrating them into portions of useful knowledge (e.g., Core Conflictual Relationship Theme in Luborsky \& Barrett, 2007; Shedler-Westen Assessment Procedure in Shedler \& Westen, 2007; Referential Activity Rating Scales in Bucci, Kabasakalian-McKay, \& Graham, 2004).

6. Maintain awareness of the role of sociocultural factors in the prevalence and development of psychopathology. This can help to prevent cognitive biases and stereotypic thinking from clinicians, which influences not only their interactions with patients (and research participants) but also the case conceptualization process, effect, and communication.

Although these challenges are difficult to meet in their entirety, the studies cited in this volume address them to some extent. The articles are connected by the fact that their authors refer to psychological theory (often paradigmatic) and face methodological problems resulting from insight into the complex nature of the studied phenomena rather than stopping at the descriptive level.

Mentalization and personality disorders are chief examples of the complexity of mental phenomena (Allen, Fonagy, \& Bateman, 2008; Górska \& Cierpiałkowska, 2016; Cierpiałkowska \& Soroko, 2014). Mentalization and its distortions most often occur in the context of personality disorders, especially borderline personality disorder, which is why studies on borderline mentalization are carried out on a large scale. However, the results of these studies are inconsistent, creating a chaotic mosaic with rather surprising and contradictory theoretical results and with a risk of a simplified and selective use of the mentalization construct. An attempt to organize and comment on this knowledge is made by Jańczak (2018), who postulates that systematizing theoretical and empirical knowledge concerning mentalization in borderline personality disorder requires reference to the complexity of mentalization as a construct, the research methods used to study it, and the heterogeneity of the studied groups. Understanding these fundamental and nuanced issues allows for reflection on what aspect of mentalization is being studied, under which conditions, and toward whom it is used in research or in practice.

The complicated nature of mentalization is also examined by Górska (2018). Referring to hierarchical and systemic models of the mind, Górska discusses the stability and changeability of mentalization, and she examines the rules and factors on which disturbances of mentalization depend. She also presents a proposal to classify the dynamics of mentalization. On the basis of research participants' statements, she analyzes the dynamics of mentalization depending on the interaction of stimuli and the content of internal representations, and she interprets the results of her research in the context of the potential mechanism responsible for the breakdown of mentalization.

Soroko and Cierpiałkowska (2018) present a move beyond the descriptive level toward the explanatory level and a turn from symptoms toward mental (intrapsychic) structures. The authors treat relational patterns not as interpersonal relations but as internal representations. By analyzing autobiographical narrations about close relationships, they examine the features of relational patterns in connection to the level of personality organization. The results of their study discussed in the context of specific theoretical assumptions of Kernberg's theory and their review of the empirical literature suggest that a promising approach is to search for an understanding of personality disorders with regard to the explanatory (theoretical) rather than the descriptive (symptomatic) level.

The complexity of the phenomenon of psychopathy in the context of self-presentation is shown by Groth and Kleka (2018). In their exploratory research, they use a self-report method to measure psychopathy and include instructions to distort the self-image toward better or worse adaptation. They identify several patterns of "faking bad" (simulation) and "faking good" (dissimulation). The pattern that is most strongly associated with psychopathy turns out to be different from the form of self-image distortion that is frequently observed in clinical practice. This research is a voice in the discussion on the diagnosis and measurement of psychopathy in the context of the direct relationship (as in an interview) and in the context of self-description and their different consequences in a clinical setting.

Gawda (2018) urges us to examine personality disorders in the light of two questions: what is the social and cultural specificity (e.g., income rate, individualism vs. collectivism), and what are the reasons for psychological unity (especially neurobiological and evolutionary mechanisms) of personality disorders? The article helps to open up an understanding of "the other" in a world whose virtue is openness and whose potential is mobility. In the long term, it also encourages caution in practical diagnostic tasks where cultural factors appear to be important. 
Zinczuk-Zielazna, Kleka, and Obrębska (2018) found that participants' loquaciousness while speaking in front of an audience was more strongly influenced by currently experienced emotions than by anxiety as a stable personality trait. This finding highlights the role of social context in emotional activation. It is important for this relationship to be detected precisely in experimental models. The study also includes a detailed and sensitive analysis of facial emotional expressions.

We hope that this special issue will provide an opportunity to discuss the possibilities of moving beyond descriptions in clinical psychology while at the same time remaining at a high scientific and practical level.

\section{REFERENCES}

Allen, J. G., Fonagy, P., \& Bateman, A. W. (2008). Mentalizing in clinical practice. Washington, DC: American Psychiatric Publishing, Inc.

American Psychological Association (2018). Clinical Psychology. Retrieved from http://www.apa.org/ ed/graduate/specialize/clinical.aspx [accessed July 20, 2018]

Baker, R. (2018). Emotional processing. Retrieved from http://emotionalprocessing.org

Baltes, P. B. (1998). Theoretical propositions of lifespan developmental psychology: On the dynamics between growth and decline. In M. P. Lawton \& T. A. Salthouse (Eds.), Essential papers on the psychology of aging (pp. 86-123). New York, NY: New York University Press.

Brzeziński, J. (2017). Data integration levels. Between scientific research and professional practice in clinical psychology. Current Issues in Personality Psychology, 5, 163-171. doi: https://doi. org/10.5114/cipp.2017.70142

Bucci, W., Kabasakalian-McKay, R., \& Graham, E. (2004). Scoring referential activity instructions for use with transcripts of spoken texts. Unpublished manual.

Cha, C. B., \& DiVasto, K. A. (2017). Introduction: Applying clinical psychological science to practice. Journal of Clinical Psychology: In Session, 73, 504510. doi: 10.1002/jclp.22448

Chefetz, R. A. (2013). A fluctuating capacity to mentalize: Affect scripts and self-state systems as (not so) "strange attractors": A discussion of Margy Sperry's "Putting our heads together: Mentalizing systems”. Psychoanalytic Dialogues, 23, 708-714.

Cierpiałkowska, L., Groth, J., \& Kleka, P. (2018). Level of personality integration in psychopathy. Psychiatria Polska, 52, 55-67.

Cierpiałkowska, L., \& Sęk, H. (2016). Naukowe i społeczne wyzwania dla psychologii klinicznej. Roczniki Psychologiczne, 19, 401-418. doi: 10.18290/rpsych. 2016.19.3-1pl
Cierpiałkowska, L., \& Soroko, E. (Eds.) (2014). Zaburzenia osobowości. Problemy diagnozy klinicznej [Personality disorders. Clinical diagnosis]. Poznań: Wydawnictwo Naukowe UAM.

Garb, H. N. (2010). The social psychology of clinical judgment. In J. E. Maddux \& J. P. Tangney (Eds.), Social psychological foundations of clinical psychology (pp. 297-311). New York: Guilford Publications, Inc.

Gawda, B. (2018). Cross-cultural studies on the prevalence of personality disorders. Current Issues in Personality Psychology, 4, 318-329.

Gelo, O. G., \& Salvatore, S. (2016). A dynamic systems approach to psychotherapy: A meta-theoretical framework for explaining psychotherapy change processes. Journal of Counseling Psychology, 63, 379-395. doi: 10.1037/cou0000150

Górska, D. (2018). Fluctuations of mentalization in the context of relational stimuli and representational contents. Current Issues in Personality Psychology, 4, 279-291.

Górska, D., \& Cierpiałkowska, L. (2016). Mentalizacja jako stan i jako cecha - perspektywa strukturalno-procesualna [Mentalization as a state and as a trait - the structural-processual perspective]. In L. Cierpiałkowska \& D. Górska (Eds.), Mentalizacja z perspektywy rozwojowej i klinicznej [Mentalization from the developmental and clinical perspective] (pp. 13-41). Poznań: Wydawnictwo Naukowe UAM.

Górska, D., \& Soroko, E. (2017). Between verbalization and reflection: Referential activity and narrative processes in borderline personality organization. Psychoanalytic Psychology, 34, 422-433.

Groth, J., \& Kleka, P. (2018). Patterns of intentional faking in questionnaire-based study of psychopathy. Current Issues in Personality Psychology, 4, 305-317.

Jańczak, M. (2018). Mentalization in borderline individuals: An attempt to integrate contradictory research results. Current Issues in Personality Psychology, 4, 266-278.

Luborsky, L., \& Barrett, M. S. (2007). The core conflictual relationship theme: A basic case formulation method. In T. D. Eells (Ed.), Handbook of psychotherapy case formulation (pp. 105-135). New York: Guilford Press.

Mergenthaler, E. (2008). Resonating minds: A school-independent theoretical conception and its empirical application to psychotherapeutic processes. Psychotherapy Research, 8, 109-126. doi: 10.1080/10503300701883741

Mullins-Sweatt, S. N., Lengel, G. J., \& DeShong, H. L. (2016). The importance of considering clinical utility in the construction of a diagnostic manual. Annual Review of Clinical Psychology, 12, 133-155. doi: 10.1146/annurev-clinpsy-021815-092954 
Pervin, L. A. (2001). A dynamic systems approach to personality. European Psychologist, 6, 172-176. doi: 10.1027//1016-9040.6.3.172

Ready, R. E., \& Santorelli, G. D. (2014). Values and goals in clinical psychology training programs: Are practice and science at odds? Professional Psychology: Research and Practice, 45, 99-100. doi: 10.1037/a0036081

Reese, R. J., González, E. G., Clements-Hickman, A. L., Clemons, J. M., Farook, M. W., \& Conoley, C. W. (2017). The psychotherapy researcher-practice relationship: Through a clinical supervision lens. Counselling Psychology Quarterly, 30, 290-307. doi: http://dx.doi.org/10.1080/09515070.2017.1285270

Shedler, J., \& Westen, D. (2007). The Shedler-Westen assessment procedure (SWAP): Making personality diagnosis clinically meaningful. Journal of Personality Assessment, 89, 41-55.

Smith, K. V., \& Thew, G. R. (2017). Conducting research in clinical psychology practice: Barriers, facilitators, and recommendations. British Journal of Clinical Psychology, 56, 347-356. doi: 10.1111/ bjc. 12142

Soroko, E., \& Cierpiałkowska, L. (2018). Levels of personality organization and internal relational patterns. Current Issues in Personality Psychology, 4, 292-304

Sperry, M. (2013). Putting our heads together: Mentalizing systems. Psychoanalytic Dialogues, 23, 683-699.

Westen, D., \& Weinberger, J. (2005). In praise of clinical judgment: Meehl's forgotten legacy. Journal of Clinical Psychology, 61, 1257-1276.

Zhang, F., \& Labouvie-Vief, G. (2004). Stability and fluctuation in adult attachment style over a 6-year period. Attachment \& Human Development, 6, 419-437.

Zinczuk-Zielazna, J., Kleka, P., \& Obrębska, M. (2018). Verbal fluency and emotional expression in young women differing in their styles of coping with threatening stimuli. Current Issues in Personality Psychology, 4, 330-342. 